\section{CASE OF PROLONGED AND PROFOUND SLEEP, OCCURRING AT INTERVALS DURING TWENTY YEARS.}

By W. G. Gimson, M.D., Witham, Essex.

J. C., aged 44, a farmer, had never been ill, beyond what he describes as a slight cold.

In 1842 or 1843 , the patient after getting very wet and not changing his clothes, suffered from a severe cold, which was followed by long and deep sleeps, the dura. tion of each sleep being more than twelve hours, and the sleep of so profound a nature that it was found impos. sible to awake him. This attack lasted nine or ten months, and ceased upon the setting in of very wet weather.

In 1848 , he experienced a similar attack after catching cold. This attack was more severe than the former, was accompanied by occasional trismus, lasted over a period of eighteen months, and ceased upon the appearance of wet weather.

The present attack dates from the 11th or 12th of May, 1860. At this time the patient got very wet at a fair, and experienced considerable pain in all his limbs, and especially in his back. These symptoms, I am informed, were cured by small doses of Gregory's powder. About a week afterwards, the patient became very drowsy ; and when he was once asleep it was found impossible to awaken him, the duration of the sleep being from twelve to twenty-four hours.

I was called to see him after the attack had existed for some time, and found him in bed apparently sound asleep, lying upon his left side; breathing quietly, respirations 18 in a minute; pulse 64 , regular, feeble; skin generally warm and perspiring; hands and feet somewhat cold; complexion dusky: there was a peculiar twitching of the eyelids, and upon separating them the pupils were seen slightly dilated, and fixed.

After calling loudly in his ears, pulling him over from one side to the other, pinching his nails, etc., be was awakened by touching the conjunctiva with my fingernail.

He awoke with a slight exclamation of surprise, and sat up. The pulse was slightly accelerated; the countenance heavy; the pupils were dilated, but acting under stimu. lus of light; his voice was low and husky; the mucous membrane of the fauces was slightly inflamed; his tongue was clean and moist; the bowels had been open twice the preceding evening, while he was awake. His urine was reported to be high coloured, and turbid on cooling.

He bad no pains nor uneasy sensation to complain of, except a deeply seated pricking across the forehead, generally felt when awake.

He now passes about forty hours out of forty-eight in sleep; and has been known to sleep more than three days without taking food; the longest time, as I am in. formed, being eighty.four hours.

He generally awakes as the evening approaches; never dreams, or, if he does, the mind retains no impression of so doing; he generally goes to sleep upon the right side, soon turns over on to the left, and so remains until he awakes.

He has never voided urine nor stool even during his longest sleep, although he has several times laboured under diarrhœe during the present attack.

His memory is good; he inquires after friends whom he saw when last awake, and this before time has elapsed, or circumstance has occurred, to recall the fact to his mind. And he is now as capable (when awake) of transacting business, or of any calculation, as he was at any period of his life.

Weather and the state of the atmosphere seem to ex. ercise a direct influence upon him; he is always more wakeful, and remains longer awake during wet and dull weather than at any other time, and he will frequently awake and foretell a coming storm.

During the preceding two attacks he was bled, blistered, etc., and all the experiments were tried upon him which medicine could suggest; but with no avail. My opinion was asked as to the advisability of a seton; and as I could not see any benefit likely to arise from that mode of treatment, I gave an opinion against it. Upon being asked, what I could recommend as likely to be of service in this case? I felt how little I could suggest in the present state of things. The appetite was good; the functions of the stomach and alimentary canal of the liver and kidneys were carried on to all appearance efficiently; the heart-sounds were clear but feeble ; respiration was free but shallow; the surface was generally warm. What could be of use? I confess I was puzzled; nor could $I$, by searching through books, or thinking upon the case, arrive at anything like a satisfactory conclusion.

The only case I can find at all approaching the one I have related, is that by Dr. Oliver, F.R.S., of "An Extraordinary Sleepy Person," at 'Timsbury, near Bath, May 1694.

This person seems to have been more of a somnambulist than my patient; and although he slept as profoundly and so long as a month at a time, still he managed to eat and drink during sleep. This state of things occurred at intervals for some four years; and during that time he was bled, blistered, scarified, etc., but to no pur. pose. The sleep in this case was so profound that one visitor thrust a pin into the patient's arm down to the bone without awakening him. During one attack, also, he suffered from trismus.

The physiology of sleep is too lengthy a subject to enter upon in a paper like the present. I have simply related facts as far as I am able in the case of $\mathrm{my}$ pa. tient, and have done so with the hope that some one may suggest a mode of proceeding likely to be of use in the treatment of this disease, for disease it certainly is.

\section{CASE OF PHLEGMASIA DOLENS FOLLOWING AN OPERATION FOR HAMORRHOIDS.}

\section{By Hexry Ewex, Esq., Long Sutton.}

Mrs. C., aged 48, a farmer's wife, of active habits, has had seven children, the last 14 years of age, but still menstruates. She had had hæmorrhoids upwards of twenty years, and had suffered very great losses of blood.

June 17th, 1862. She was pale and anæmic, with a very quick pulse and great debility. There was a loose pendulous flap around the anus, and a pile of the size and colour of a cherry projecting therefrom. Nitric acid was applied to the pile.

June 23rd. The pendulous flap was removed by excision. The operation was followed by some protrusion from the anus, and superficial sloughing of the pro. truded part; but the parts healed kindly in the course of a month. Just three days before the expiration of a month, phlegmasia dolens supervened, affecting the left lower limb. There were great pain and tenderness in the groin, and along the course of the femoral vein, gradually extending downwards to the ham and ealf of the leg, and considerable œdema of the whole limb.

August 31st. There remained much œdema of the left leg, and inability to walk. Her general health was much improved.

May 1863. She had an excellent recovery, and remains quite well. 